\title{
Coronary Angiography in Patients with and without STEMI Following Out-of-Hospital Cardiac Arrest
}

\author{
Martin Christ, Katharina Isabel von Auenmueller, Wolfgang Dierschke, \\ Jan Peter Noelke, Thomas Butz, Jeanette Liebeton, Hans-Joachim Trappe \\ Department of Cardiology and Angiology, Marienhospital Herne, Ruhr-University Bochum, Germany \\ Email: martin.christ@marienhospital-herne.de
}

Received 14 October 2014; revised 5 November 2014; accepted 27 November 2014

Copyright (C) 2014 by authors and Scientific Research Publishing Inc.

This work is licensed under the Creative Commons Attribution International License (CC BY). http://creativecommons.org/licenses/by/4.0/

(c) (7) Open Access

\begin{abstract}
Introduction: Little is known about discrepancies between patients who present with or without STEMI following out-of-hospital cardiac arrest (OHCA). Material and Methods: All patients with OHCA who were admitted to our hospital between January 1st 2008 and December 31st 2013 were classified according to their initial laboratory and electrocardiographic findings into STEMI, NSTEMI or no ACS. Results: Overall, 147 patients [32 STEMI $(21.8 \%), 28$ NSTEMI $(19.0 \%)$ and 87 no ACS $(59.2 \%)]$ were included with a mean age of $63.7 \pm 13.3$ years; there were 84 men $(57.1 \%)$ and $63(42.9 \%)$ women. Of these, 63 patients $(51.7 \%)$ received coronary angiography [29 STEMI (90.6\%), 9 NSTEMI (32.1\%) and 38 no ACS $(43.7 \%)]$ showing a high prevalence of coronary artery disease (CAD) [28 STEMI (96.6\%), 9 NSTEMI (100.0\%) and 26 no ACS (68.4\%)] requiring percutaneous coronary intervention (PCI) in 52 cases [28 STEMI (96.6\%), 8 NSTEMI (88.9\%) and 16 no ACS (42.1\%)]. Discussion: Coronary angiography immediately after hospital admission is feasible if all are prepared for potential further resuscitation efforts during cardiac catheterization. Primary focus on haemodynamic stabilisation may reduce the rates of coronary angiographies in patients following OHCA. Altogether, our data support the call for immediate coronary angiography in all patients following OHCA irrespective of their initial laboratory or electrocardiographic findings.
\end{abstract}

\section{Keywords}

Out-of-Hospital Cardiac Arrest, OHCA, Myocardial Infarction, STEMI, NSTEMI, Coronary Angiography, Resuscitation 


\section{Introduction}

There is a poor predictive value of clinical and electrocardiographic data, such as chest pain or ST-segment elevation (STEMI), for coronary-artery occlusion in patients following out-of-hospital cardiac arrest (OHCA). Therefore, the current Guidelines of the European Resuscitation Council emphasise early coronary angiography in all post-cardiac arrest patients who are suspected of having coronary artery disease irrespective of their electrocardiographic findings [1].

By now, few studies tried do further differentiate between patients with or without STEMI following OHCA. Pleskot et al. described ST-segment elevations as one of the strongest predictors for long-term survival following OHCA [2] and Anyfantakis et al. discussed whether the presence of ST elevation on admission might be used to triage OHCA patients to emergency angiography with a view to percutaneous coronary intervention (PCI) or not [3].

However, all these studies work on the basis of small patient's sizes: 26 patients with STEMI in the study of Pleskot et al. [2]; 27 patients with any type of myocardial infarction in the study of Anyfantakis et al. [3].

We, therefore, see the need for further studies on this subject to learn more about the discrepancies between patients who present with or without STEMI following OHCA.

\section{Methods}

\subsection{Data Collection}

All individuals with OHCA who were admitted to our hospital between January 1st 2008 and December 31st 2013 were identified by analysis of our central admission register. Individual patient data were collected from the patient's health records and anonymously stored on a central database. Statistical analysis was performed with the Statistical Package for Social Science (SPSS 22.0, IBM, Armonk, NY, USA). Continuous variables are expressed as the mean $\pm \mathrm{SD}$, comparisons of categorical variables among groups were conducted using Chisquare tests or student's t-test. Data collection and analysis was approved by the local ethical review committee.

\subsection{Definition of Myocardial Infarction}

ST elevation myocardial infarction (STEMI) was defined as new or presumably new significant ST-T changes in at least two corresponding leads or new Left Bundle Branch Block (LBBB) in combination with a rise and/or fall of cardiac biomarker values like troponin with at least one value above the 99th percentile of the upper reference limit during follow-up, but also in patients with cardiac death and presumably new ECG changes or new LBBB but death occurring before blood cardiac biomarker values would be increased [4].

Non-ST elevation myocardial infarction (NSTEMI) was defined as a rise and/or fall of cardiac biomarker values like troponin with at least one value above the 99th percentile of the upper reference limit but without significant ECG changes [4] [5].

If patients did not comply with one of the above described criteria, they were classified as without acute coronary syndrome (no ACS).

\subsection{Treatment Strategy}

In patients with suspected cardiac cause of death, coronary angiography was attempted as soon as possible, except in haemodynamically unstable patients where we primarily aimed at haemodynamic stabilisation.

In patients who received coronary angiography, catheterisation was performed according to standard techniques. If a recent coronary-artery stenosis was found, coronary angioplasty was attempted, unless the infarctrelated artery was too small or the operator considered the procedure to be technically impossible. Standard resuscitative and stabilisation procedures were continued during the procedure if necessary.

\section{Results}

Altogether, 204 patients were admitted to our hospital between January 1st 2008 and December 31st 2013 following OHCA. Of these, 29 patients were excluded from further analysis due to absent 12-lead ECG as a consequence of incessant resuscitation efforts, 16 patients presented an ECG that could not be assessed according to ST segment elevation: four patients presented with continuous ventricular pacemaker stimulation, seven patients 
with ventricular tachycardia and five patients with ventricular escape rhythm, and 12 patients had to be excluded due to missing or incomplete data. Clinical data of the remaining 147 patients are summarised in Table 1 .

\subsection{Patient's Characteristics}

There were 84 men $(57.1 \%)$ and 63 women $(42.9 \%)$ with a mean age of $63.7 \pm 13.3$ years [range: 31 - 88 years]. Overall, there were 106 witnessed cardiac arrests $(72.1 \%)$, lay resuscitation was attempted in 72 patients $(49.0 \%)$ and 53 patients (36.1\%) presented with an initial shockable rhythm.

Overall, 32 patients presented with an ST elevation myocardial infarction (STEMI), and 28 patients with a non-ST elevation myocardial infarction. Creatine kinase (CK) was $415.6 \pm 733.0 \mathrm{U} / 1$ [range: $38-3898 \mathrm{U} / 1$ ] and Creatine Kinase Muscle Brain (CK-MB) was $145.8 \pm 153.4$ (U/l) [range: 24 - 715]. Troponin was $3.5 \pm 10.0$ (ng/ml) [range: $0.0-50.0]$.

Cardiac catheterisation was performed in 76 patients $(51.7 \%), 63$ patients $(42.9 \%)$ showed coronary artery disease (CAD), and 52 patients (35.4\%) received percutaneous coronary intervention (PCI). Resuscitation during cardiac catheterisation was required in four patients (5.2\%).

Also, 76 patients $(51.7 \%)$ received mild therapeutic hypothermia (MTH, $33^{\circ} \mathrm{C}$ for 24 hours, rewarming $0.3^{\circ} \mathrm{C}$ $/ h)$ and 61 patients $(41.5 \%)$ were discharged alive.

\subsection{STEMI}

Here, 32 patients presented with STEMI following OHCA; 16 of them (50.0\%) were discharged alive, while 16

Table 1. Characteristics of those 147 patients following OHCA who could be included in our study.

\begin{tabular}{|c|c|}
\hline & All Patients $(n=147)$ \\
\hline Male & $84(57.1 \%)$ \\
\hline Age (Years) & $63.7 \pm 13.3$ \\
\hline [range] & {$[31.0-88.0]$} \\
\hline Witnessed cardiac arrest & $106(72.1 \%)$ \\
\hline Lay resuscitation & $72(49.0 \%)$ \\
\hline Initial shockable rhythm & $53(36.1 \%)$ \\
\hline ST elevation myocardial infarction (STEMI) & $32(21.8 \%)$ \\
\hline Non-ST elevation myocardial infarction (NSTEMI) & $28(19.0 \%)$ \\
\hline Creatine kinase $(\mathrm{CK})(\mathrm{U} / 1)$ [range] & $\begin{array}{c}415.6 \pm 733.0 \\
{[38.0-3898.0]}\end{array}$ \\
\hline Creatine kinase Muscle Brain (CK-MB) (U/1) [range] & $\begin{array}{l}145.8 \pm 153.4 \\
{[24.0-715.0]}\end{array}$ \\
\hline Troponin (ng/ml) [range] & $\begin{array}{c}3.5 \pm 10.0 \\
{[0.0-50.0]}\end{array}$ \\
\hline Coronary angiography & $76(51.7 \%)$ \\
\hline Coronary artery disease (CAD) & $63(42.9 \%)$ \\
\hline Percutaneous coronary intervention (PCI) & $52(35.4 \%)$ \\
\hline RAMUS interventricularis anterior (RIVA) & $18(12.2 \%)$ \\
\hline Ramus circumflexus (RCX) & $7(4.8 \%)$ \\
\hline Right coronary artery (RCA) & $13(8.8 \%)$ \\
\hline Multi vessel intervention (MVI) & $14(9.5 \%)$ \\
\hline Resuscitation during cardiac catheterisation & $4(5.2 \%)$ \\
\hline Mild therapeutic hypothermia (MTH) & $76(51.7 \%)$ \\
\hline Discharged alive & $61(41.5 \%)$ \\
\hline
\end{tabular}


patients $(50.0 \%)$ died in hospital. The only difference between these two groups was a higher Creatine kinase among patients who died $(968.9 \pm 1294.6 \mathrm{U} / 1$ vs. $280.8 \pm 236.1 \mathrm{U} / \mathrm{l})(\mathrm{p}=0.040)$. No differences could be seen in gender, age, rate of witnessed arrest, lay resuscitation, initial shockable rhythm, Creatine kinase Muscle Brain, Troponin at admission, cardiac catheterisation, coronary artery disease, percutaneous coronary intervention, necessity of resuscitation during cardiac catheterisation and application of mild therapeutic hypothermia (Table 2).

\subsection{NSTEMI}

Here, 28 patients following OHCA presented with NSTEMI; 7 of them (25.0\%) survived until hospital discharge, while 21 died in hospital (75.0\%). The only difference between patients with NSTEMI who survived until hospital discharge and patients who died in hospital was a higher rate of cardiac catheterisation among those patients who could be discharged alive $(71.4 \%$ vs. $19.0 \%)(p=0.010)$. No differences could be seen in gender, age, rate of witnessed arrest, lay resuscitation, initial shockable rhythm, Creatinine kinase, Creatinine kinase Muscle Brain, Troponin at admission, coronary artery disease, percutaneous coronary intervention, necessity of resuscitation during cardiac catheterisation and the application of mild therapeutic hypothermia (Table 2).

\subsection{No ACS}

Overall, 87 patients following OHCA presented with neither STEMI nor NSTEMI. In this group, 38 patients (43.7\%) survived until hospital discharge, while 49 patients (56.3\%) died in hospital. Patients who survived until

Table 2. Differences between patients who presented with STEMI, NSTEMI or without ACS following out-of-hospital cardiac-arrest.

\begin{tabular}{|c|c|c|c|c|c|c|c|c|c|}
\hline & \multicolumn{3}{|c|}{ STEMI $(n=32)$} & \multicolumn{3}{|c|}{ NSTEMI $(n=28)$} & \multicolumn{3}{|c|}{ No $\operatorname{ACS}(n=87)$} \\
\hline & $\begin{array}{c}\text { Discharged } \\
\text { Alive } \\
(n=16)\end{array}$ & $\begin{array}{l}\text { Died in } \\
\text { Hospital } \\
(\mathrm{n}=16)\end{array}$ & $\mathrm{p}$ & $\begin{array}{c}\text { Discharged } \\
\text { Alive } \\
(n=7)\end{array}$ & $\begin{array}{l}\text { Died in } \\
\text { Hospital } \\
(\mathrm{n}=21)\end{array}$ & $\mathrm{p}$ & $\begin{array}{c}\text { Discharged } \\
\text { Alive } \\
(\mathrm{n}=38)\end{array}$ & $\begin{array}{l}\text { Died in } \\
\text { Hospital } \\
(n=49)\end{array}$ & $\mathrm{p}$ \\
\hline Male & $11(68.8 \%)$ & $9(56.3 \%)$ & 0.654 & $6(85.7 \%)$ & $12(57.1 \%)$ & 0.172 & $23(60.5 \%)$ & $23(46.9 \%)$ & 0.208 \\
\hline Age (Years) & $59.8 \pm 12.7$ & $67.4 \pm 13.6$ & 0.108 & $67.3 \pm 10.3$ & $70.3 \pm 13.1$ & 0.589 & $63.5 \pm 15.5$ & $75.6 \pm 12.1$ & $<0.001$ \\
\hline Witnessed cardiac arrest & $14(87.5 \%)$ & $13(81.3 \%)$ & 0.831 & $6(85.7 \%)$ & $16(76.2 \%)$ & 0.695 & $29(76.3 \%)$ & $28(57.1 \%)$ & 0.175 \\
\hline Lay resuscitation & $10(62.5 \%)$ & $8(50.0 \%)$ & 0.476 & $5(71.4 \%)$ & $7(33.3 \%)$ & 0.078 & $23(60.5 \%)$ & $19(38.8 \%)$ & 0.064 \\
\hline Initial shockable rhythm & $11(68.8 \%)$ & $10(62.5 \%)$ & 0.690 & $5(71.4 \%)$ & $6(28.6 \%)$ & 0.055 & $15(39.5 \%)$ & $6(12.2 \%)$ & 0.002 \\
\hline Creatine kinase $(\mathrm{CK})(\mathrm{U} / \mathrm{l})$ & $280.8 \pm 236.1$ & $986.9 \pm 1294.6$ & 0.040 & $690.1 \pm 529.6$ & $590.0 \pm 971.5$ & 0.798 & $171.4 \pm 334.3$ & $\begin{array}{c}161.6 \pm \\
197.5\end{array}$ & 0.871 \\
\hline $\begin{array}{l}\text { Creatine kinase Muscle Brain (CK-MB) } \\
(\mathrm{U} / \mathrm{l})\end{array}$ & $91.6 \pm 35.9$ & $210.6 \pm 200.3$ & 0.065 & $170.8 \pm 75.5$ & $160.9 \pm 148.6$ & 0.879 & $74.8 \pm 51.8$ & $77.2 \pm 35.5$ & 0.887 \\
\hline Troponin (ng/ml) & $1.4 \pm 2.2$ & $7.2 \pm 12.9$ & 0.087 & $10.0 \pm 15.9$ & $5.0 \pm 11.0$ & 0.354 & $0.1 \pm 0.1$ & $0.1 \pm 0.1$ & 0.068 \\
\hline Coronary angiography & $15(93.8 \%)$ & $14(87.5 \%)$ & & $5(71.4 \%)$ & $4(19.0 \%)$ & & $24(63.2 \%)$ & $14(28.6 \%)$ & \\
\hline$<1$ hour & $8(\%)$ & $6(\%)$ & & $3(\%)$ & $1(\%)$ & & $8(\%)$ & $5(\%)$ & \\
\hline$<4$ hours & $6(\%)$ & $8(\%)$ & 0.544 & $1(\%)$ & $1(\%)$ & 0.010 & $4(\%)$ & $6(\%)$ & 0.002 \\
\hline$<24$ hours & $1(\%)$ & $0(0.0 \%)$ & & $0(0.0 \%)$ & $0(0.0 \%)$ & & $5(\%)$ & $2(\%)$ & \\
\hline$>24$ hours & $0(0.0 \%)$ & $0(0.0 \%)$ & & $1(\%)$ & $2(\%)$ & & $7(\%)$ & $1(\%)$ & \\
\hline Coronary artery disease (CAD) & $14(87.5 \%)$ & $14(87.5 \%)$ & 1.000 & $5(71.4 \%)$ & $4(19.0 \%)$ & 0.171 & $14(36.8 \%)$ & $12(24.5 \%)$ & 0.163 \\
\hline Percutaneous coronary intervention $(\mathrm{PCI})$ & $14(87.5 \%)$ & $14(87.5 \%)$ & & $4(57.1 \%)$ & $4(19.0 \%)$ & & $8(21.1 \%)$ & $8(16.3 \%)$ & \\
\hline $\begin{array}{l}\text { RAMUS interventricularis anterior } \\
\text { (RIVA) }\end{array}$ & $6(37.5 \%)$ & $4(25.0 \%)$ & & $2(28.6 \%)$ & $0(0.0 \%)$ & & $3(7.9 \%)$ & & \\
\hline RAMUS circumflexus (RCX) & $1(6.3 \%)$ & $2(12.5 \%)$ & 1.000 & $1(14.3 \%)$ & $2(9.5 \%)$ & 0.053 & $1(2.6 \%)$ & $0(0.0 \%)$ & 0.552 \\
\hline Right coronary artery (RCA) & $2(12.5 \%)$ & $6(37.5 \%)$ & & $1(14.3 \%)$ & $0(0.0 \%)$ & & $2(5.3 \%)$ & $2(4.1 \%)$ & \\
\hline Multi vessel intervention (MVI) & $5(31.3 \%)$ & $2(12.5 \%)$ & & $0(0.0 \%)$ & $2(9.5 \%)$ & & $2(5.3 \%)$ & $3(6.1 \%)$ & \\
\hline $\begin{array}{l}\text { Resuscitation during cardiac } \\
\text { catheterization }\end{array}$ & $1(6.3 \%)$ & $3(18.8 \%)$ & 0.285 & $0(0.0 \%)$ & $0(0.0 \%)$ & - & $0(0.0 \%)$ & $0(0.0 \%)$ & - \\
\hline Mild therapeutic hypothermia (MTH) & $12(75.0 \%)$ & $9(56.3 \%)$ & 0.264 & $5(71.4 \%)$ & $9(42.9 \%)$ & 0.228 & $17(44.7 \%)$ & $24(49.0 \%)$ & 0.694 \\
\hline
\end{tabular}


hospital discharge were significantly younger $(63.5 \pm 15.5$ years vs. $75.6 \pm 12.1$ years $)(p<0.001)$, presented with an initial shockable rhythm more often $(39.5 \%$ vs. $12.2 \%)$ and received cardiac catheterisation more often than those patients who died $(63.2 \%$ vs. $28.6 \%)(\mathrm{p}=0.002)$. No differences could be seen in gender, rate of witnessed arrest, lay resuscitation, Creatinine kinase, Creatinine kinase Muscle Brain, Troponin at admission, coronary artery disease, percutaneous coronary intervention, necessity of resuscitation during cardiac catheterisation and the application of mild therapeutic hypothermia (Table 2).

\section{Discussion}

\subsection{Patients with STEMI Following OHCA}

STEMI following OHCA has been described as one of the strongest predictors for long-term survival, comparable to younger age or ventricular fibrillation as initial rhythm [2].

In our study that worked on this theme, there are four main findings.

First, the prevalence of relevant coronary artery stenosis is extremely high in patients with STEMI following OHCA, but almost all culprit lesions in these patients can be successfully treated by percutaneous coronary intervention [6] [7] (Table 2 and Figure 1).

Second, higher Creatine kinase levels in patients who died during follow-up might underline the necessity of shortening the coronary no-flow time (Table 2). In our study, early coronary angiography within 60 minutes according to the guidelines for the treatment of patients with STEMI [4] could be achieved in almost half of all patients with STEMI (48.3\%), irrespective the need for further airway management or haemodynamic stabilization in this special situation following OHCA.

Third, our results underline previous findings of a better prognosis of patients with STEMI following OHCA with survival rates of $50 \%$ or better [6] [8] [9]. Treating the cause of OHCA with coronary angiography and PCI obviously reduces the incidence of adverse events and decreases mortality during hospitalisation [10].

Fourth, enforcing early coronary angiography in patients with STEMI following OHCA is only feasible if all involved physicians and staff are prepared for further resuscitation efforts in the coronary laboratory (Table 2 and Figure 1).

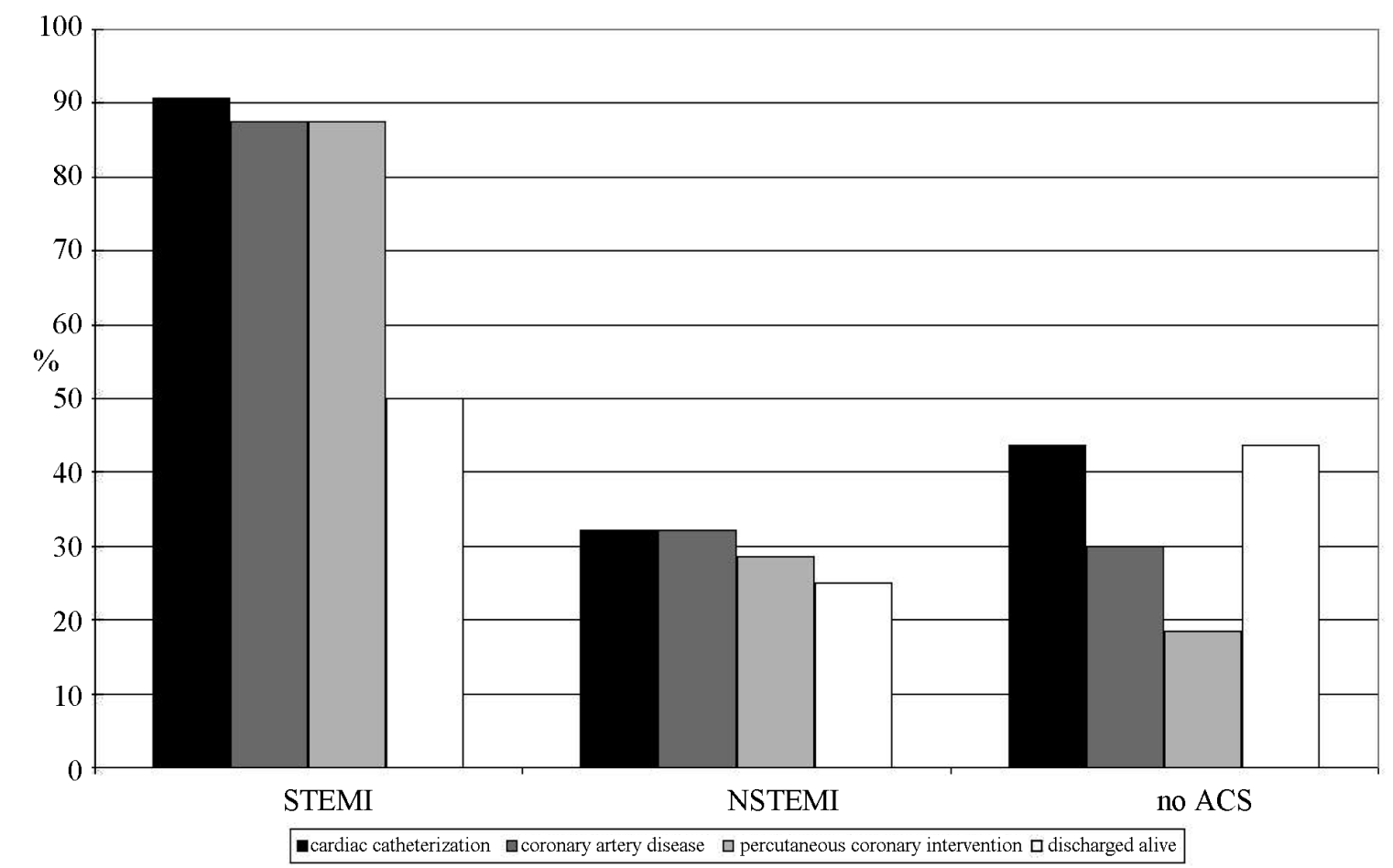

Figure 1. Survival rates in patients following OHCA depending on whether they initially present with STEMI, NSTEMI or no ACS. 


\subsection{Patients without STEMI following OHCA}

In our study, also patients who presented with NSTEMI and no ACS following OHCA showed better survival rates if they received coronary angiography (Table 2). However, in these patients coronary angiography was attempted significantly later than in patients who presented with STEMI (Table 2). In our opinion, the main reason for this delay was a primarily focus on haemodynamic stabilisation in these patients as coronary angiography in these subgroups appeared less urgent than in patients who presented with STEMI; consequently, there were no further resuscitation attempts in the coronary laboratory in these groups.

However, in comparison with a primary focus on early PCI in patients with STEMI, a delay with primary focus on haemodynamic stabilisation led to much lower rates of coronary angiography in patients with NSTEMI (32.1\%) or no ACS (43.7\%).

Of course, this is a single centre study and the rates of early coronary catheterisation and PCI vary enormously among hospitals [11]. However, our data are in line with other investigations that repetitively described rates of less than $50 \%$ for early coronary angiography if patients presented without STEMI following OHCA [12]-[14]. Following our findings, a too cautious proceeding in patients without STEMI might be one of the main reasons why there are discrepant findings and opinions about the benefit of early PCI in these patients [3] [8] [15]-[18].

However, the probability of patients who do not receive early coronary angiography on the first day after hospital admission receiving later coronary angiography during the same hospital stay was extremely low in our data $(7.5 \%)$ (Table 2). There might be several reasons for such a low rate of later coronary angiographies during follow-up: infections, sepsis, respiratory insufficiency, kidney injury, patient's decision, or maybe an obvious extra-cardiac cause of OHCA; however, the enormous discrepancies between our three groups underline the importance of the initial decision to undergo early coronary angiography or not.

Unfortunately, there are still hardly any objective data that can be used for the initial decision at admission. To date, no biomarker has been shown to correctly predict culprit coronary occlusion in OHCA patients [19] and also the dosage of cardiac troponin I at admission could not help in the decision of early coronary angiogram previously [20]. Also in our study, troponin and Creatine kinase at admission did not differ between patients without STEMI who survived and those who died during follow-up (Table 2). Only in patients with STEMI was higher Creatine kinase as an indirect marker of myocardial damage associated with worse survival rates (Table 2).

Likewise, also ST-segment analysis might have a good positive predictive value but a low negative predictive value in diagnosing the presence of acute or presumed recent coronary artery lesions [17]. In our study, 88.9\% of the patients with NSTEMI and $42.1 \%$ of the patients with no ACS who received coronary angiography also received percutaneous coronary intervention, underlining the high prevalence of relevant coronary artery stenosis in patients following OHCA, irrespective of the initial electrocardiographic or laboratory findings (Table 2).

Therefore, our results support previous statements that electrocardiographic findings after OHCA should not be considered as strict selection criteria for performing emergent coronary angiography in patients resuscitated from OHCA without an obvious extra-cardiac cause [8]. Even in the absence of ST-segment elevation on postROSC ECG, acute culprit coronary lesions may be present and considered the trigger of cardiac arrest.

\subsection{Limitations}

Our data are the result of a single centre study; rates of early coronary catheterisation and coronary intervention vary enormously between hospitals [11]. However, our data are in line with several previous investigations [12]-[14] and findings of better survival rates in younger patients and those with an initial shockable rhythm (Table 2) also affirm a representative patient population.

\section{Conclusions}

The observation of better survival rates in patients with STEMI and immediate PCI underlines the benefit of an immediate treatment of the cause of death in these patients. However, considering the high prevalence of coronary artery disease in patients who present without any electrocardiographic or laboratory signs of myocardial ischaemia, percutaneous coronary intervention may be a necessary causal treatment in many more cases.

All authors declare no conflicts of interest. 


\section{References}

[1] Nolan, J.P., Soar, J., Zideman, D.A., Biarent, D., Bossaert, L.L., Deakin, C., Koster, R.W., Wyllie, J. and Böttiger, B., ERC Guidelines Writing Group (2010) European Resuscitation Council Guidelines for Resuscitation 2010 Section 1. Executive Summary. Resuscitation, 81, 1219-1276. http://dx.doi.org/10.1016/j.resuscitation.2010.08.021

[2] Pleskot, M., Hazukova, R., Stritecka, H., Cermakova, E. and Pudil, R. (2009) Long-Term Prognosis after Out-of-Hospital Cardiac Arrest with/without ST Elevation Myocardial Infarction. Resuscitation, 80, 795-804. http://dx.doi.org/10.1016/j.resuscitation.2009.04.004

[3] Anyfantakis, Z.A., Baron, G., Aubry, P., Himbert, D., Feldman, L.J., Juliard, J.M., Ricard-Hibon, A., Burnod, A., Cokkinos, D.V. and Steg, P.G. (2009) Acute Coronary Angiographic Findings in Survivors of Out-of-Hospital Cardiac Arrest. American Heart Journal, 157, 312-318. http://dx.doi.org/10.1016/j.ahj.2008.09.016

[4] Steg, P.G., James, S.K., Atar, D., Badano, L.P., Blömstrom-Lundqvist, C., Borger, M.A., Di Mario, C., Dickstein, K., Ducrocq, G., Fernandez-Aviles, F., Gershlick, A.H., Giannuzzi, P., Halvorsen, S., Huber, K., Juni, P., Kastrati, A., Knuuti, J., Lenzen, M.J., Mahaffey, K.W., Valgimigli, M., van’t Hof, A., Widimsky, P. and Zahger, D. (2012) ESC Guidelines for the Management of Acute Myocardial Infarction in Patients Presenting with ST-Segment Elevation: The Task Force on the management of ST-segment elevation acute myocardial infarction of the European Society of Cardiology (ESC). European Heart Journal, 33, 2569-2619.

[5] Hamm, C.W., Bassand, J.P., Agewall, S., Bax, J., Boersma, E., Bueno, H., Caso, P., Dudek, D., Gielen, S., Huber, K., Ohman, M., Petrie, M.C., Sonntag, F., Uva, M.S., Storey, R.F., Wijns, W. and Zahger, D., ESC Committee for Practice Guidelines (2011) ESC Guidelines for the Management of Acute Coronary Syndromes in Patients Presenting without Persistent ST-Segment Elevation: The Task Force for the Management of Acute Coronary Syndromes (ACS) in Patients Presenting without Persistent ST-Segment Elevation of the European Society of Cardiology (ESC). European Heart Journal, 32, 2999-3054. http://dx.doi.org/10.1093/eurheartj/ehr236

[6] Zimmermann, S., Flachskampf, F.A., Alff, A., Schneider, R., Dechant, K., Klinghammer, L., Stumpf, C., Zopf, Y., Loehr, T., Brand, G., Ludwig, J., Daniel, W.G. and Achenbach, S. (2013) Out-of-Hospital Cardiac Arrest and Percutaneous Coronary Intervention for ST-Elevation Myocardial Infarction: Long-Term Survival and Neurological Outcome. International Journal of Cardiology, 166, 236-241. http://dx.doi.org/10.1016/j.ijcard.2011.11.029

[7] Sideris, G., Voicu, S., Yannopoulos, D., Dillinger, J.G,, Adjedj, J., Deye, N., Gueye, P., Manzo-Silberman, S., Malissin, I., Logeart, D., Magkoutis, N., Capan, D.D., Makhloufi, S., Megarbane, B., Vivien, B., Cohen-Solal, A., Payen, D., Baud, F.J. and Henry, P. (2014) Favourable 5-Year Post-Discharge Survival of Comatose Patients Resuscitated from Outof-Hospital Cardiac Arrest, Managed with Immediate Coronary Angiogram on Admission. European Heart Journal: Acute Cardiovascular Care, 3, 183-191. http://dx.doi.org/10.1177/2048872614523348

[8] Zanuttini, D., Armellini, I., Nucifora, G., Grillo, M.T., Morocutti, G., Carchietti, E., Trillò, G., Spedicato, L., Bernardi, G. and Proclemer, A. (2013) Predictive Value of Electrocardiogram in Diagnosing Acute Coronary Artery Lesions among Patients with Out-of-Hospital-Cardiac-Arrest. Resuscitation, 84, 1250-1254. http://dx.doi.org/10.1016/j.resuscitation.2013.04.023

[9] Marcusohn, E., Roguin, A., Sebbag, A., Aronson, D., Dragu, R., Amikam, S., Boulus, M., Grenadier, E., Kerner, A., Nikolsky, E., Markiewicz, W., Hammerman, H. and Kapeliovich, M. (2007) Primary Percutaneous Coronary Intervention after Out-of-Hospital Cardiac Arrest: Patients and Outcomes. Israel Medical Association Journal, 9, 257-259.

[10] Liu, H.W., Pan, W., Wang, L.F., Sun, Y.M., Li, Z.Q. and Wang, Z.H. (2012) Impact of Emergency Percutaneous Coronary Intervention on Outcomes of ST-Segment Elevation Myocardial Infarction Patients Complicated by Out-ofHospital Cardiac Arrest. Chinese Medicine Journal (English), 125, 1405-1409.

[11] Callaway, C.W., Schmicker, R.H., Brown, S.P., Albrich, J.M., Andrusiek, D.L., Aufderheide, T.P., Christenson, J., Daya, M.R., Falconer, D., Husa, R.D., Idris, A.H., Ornato, J.P., Rac, V.E., Rea, T.D., Rittenberger, J.C., Sears, G. and Stiell, I.G., ROC Investigators (2014) Early Coronary Angiography and Induced Hypothermia Are Associated with Survival and Functional Recovery after Out-of-Hospital Cardiac Arrest. Resuscitation, 85, 657-663. http://dx.doi.org/10.1016/j.resuscitation.2013.12.028

[12] Hollenbeck, R.D., McPherson, J.A., Mooney, M.R., Unger, B.T., Patel, N.C., McMullan Jr., P.W., Hsu, C.H., Seder, D.B. and Kern, K.B. (2014) Early Cardiac Catheterisation Is Associated with Improved Survival in Comatose Survivors of Cardiac Arrest without STEMI. Resuscitation, 85, 88-95. http://dx.doi.org/10.1016/j.resuscitation.2013.07.027

[13] Strote, J.A., Maynard, C., Olsufka, M., Nichol, G., Copass, M.K., Cobb, L.A. and Kim, F. (2012) Comparison of Role of Early (Less than Six Hours) to Later (More than Six Hours) or No Cardiac Catheterisation after Resuscitation from Out-of-Hospital Cardiac Arrest. The American Journal of Cardiology, 109, 451-454. http://dx.doi.org/10.1016/j.amjcard.2011.09.036

[14] Aurore, A., Jabre, P., Liot, P., Margenet, A., Lecarpentier, E. and Combes, X. (2011) Predictive Factors for Positive Coronary Angiography in Out-of-Hospital Cardiac Arrest Patients. European Journal of Emergency Medicine, 18, 7376. http://dx.doi.org/10.1097/MEJ.0b013e32833d469a 
[15] Bro-Jeppesen, J., Kjaergaard, J., Wanscher, M., Pedersen, F., Holmvang, L., Lippert, F.K., Møller, J.E., Køber, L. and Hassager, C. (2012) Emergency Coronary Angiography in Comatose Cardiac Arrest Patients: Do Real-Life Experiences Support the Guidelines? European Heart Journal: Acute Cardiovascular Care, 1, 291-301. http://dx.doi.org/10.1177/2048872612465588

[16] Nanjayya, V.B. and Nayyar, V. (2012) Immediate Coronary Angiogram in Comatose Survivors of Out-of-Hospital Cardiac Arrest-An Australian Study. Resuscitation, 83, 699-704. http://dx.doi.org/10.1016/j.resuscitation.2011.12.004

[17] Zanuttini, D., Armellini, I., Nucifora, G., Carchietti, E., Trillò, G., Spedicato, L., Bernardi, G. and Proclemer, A. (2012) Impact of Emergency Coronary Angiography on In-Hospital Outcome of Unconscious Survivors after Out-of-Hospital Cardiac Arrest. The American Journal of Cardiology, 110, 1723-1728. http://dx.doi.org/10.1016/j.amjcard.2012.08.006

[18] Radsel, P., Knafelj, R., Kocjancic, S. and Noc, M. (2011) Angiographic Characteristics of Coronary Disease and PostResuscitation Electrocardiograms in Patients with Aborted Cardiac Arrest outside a Hospital. The American Journal of Cardiology, 108, 634-638. http://dx.doi.org/10.1016/j.amjcard.2011.04.008

[19] Geri, G., Dumas, F. and Cariou, A. (2014) Should We Perform a Coronary Angiography in All Cardiac Arrest Survivors? Current Opinion in Critical Care, 20, 273-279. http://dx.doi.org/10.1097/MCC.0000000000000093

[20] Dumas, F., Manzo-Silberman, S., Fichet, J., Mami, Z., Zuber, B., Vivien, B., Chenevier-Gobeaux, C., Varenne, O., Empana, J.P., Pène, F., Spaulding, C. and Cariou, A. (2012) Can Early Cardiac Troponin I Measurement Help to Predict Recent Coronary Occlusion in Out-of-Hospital Cardiac Arrest Survivors? Critical Care Medicine, 40, 1777-1784. http://dx.doi.org/10.1097/CCM.0b013e3182474d5e 
Scientific Research Publishing (SCIRP) is one of the largest Open Access journal publishers. It is currently publishing more than 200 open access, online, peer-reviewed journals covering a wide range of academic disciplines. SCIRP serves the worldwide academic communities and contributes to the progress and application of science with its publication.

Other selected journals from SCIRP are listed as below. Submit your manuscript to us via either submit@scirp.org or Online Submission Portal.
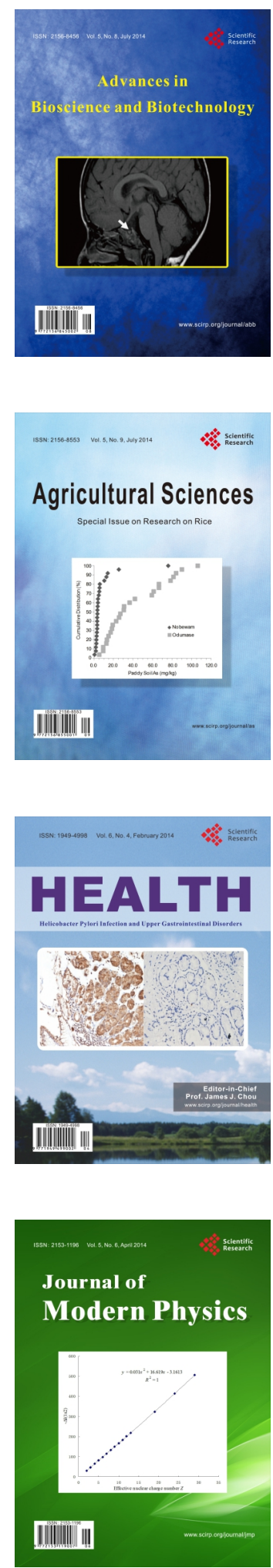
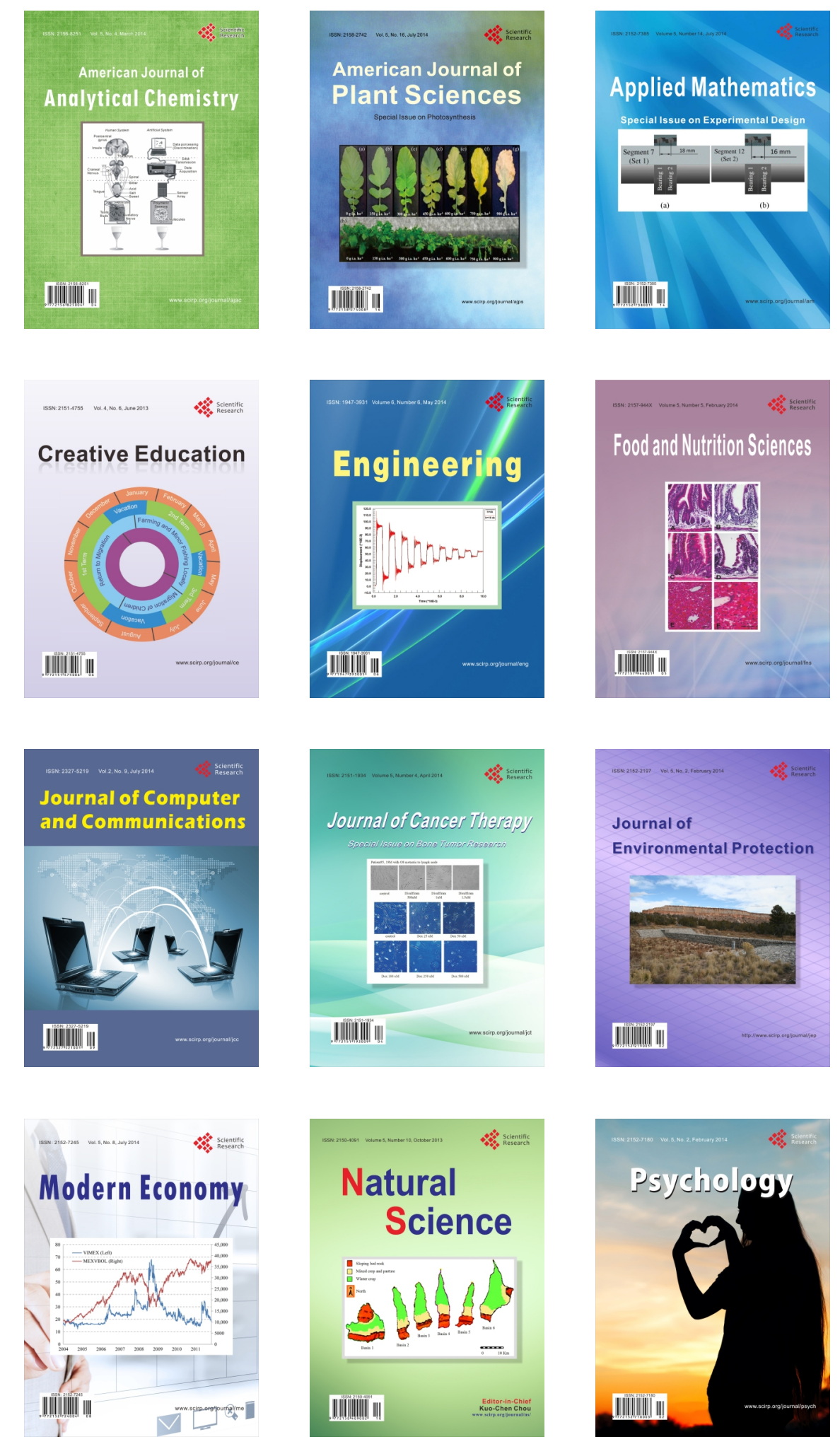